\title{
Impact of intensive training on health professionals' self-efficacy in establishing, running and maintaining a cardiac rehabilitation program
}

\author{
Barbara M. Murphy*1,2,3, Rosemary O. Higgins ${ }^{1,4}$, Michael Le Grande ${ }^{1,2}$, Alison Beauchamp ${ }^{1,5}$, Marian U. Worcester ${ }^{1,6}$, \\ Alan J. Goble ${ }^{1}$, Alun C. Jackson ${ }^{1,2,7}$ \\ ${ }^{1}$ Australian Centre for Heart Health, Melbourne, Australia \\ ${ }^{2}$ Deakin University Faculty of Health, Geelong, Australia \\ ${ }^{3}$ Department of Psychology, University of Melbourne, Australia \\ ${ }^{4}$ Department of Physiotherapy, University of Melbourne, Australia \\ ${ }^{5}$ Department of Rural Health, Monash University, Australia \\ ${ }^{6}$ Department of Epidemiology and Preventive Medicine, Monash University, Australia \\ ${ }^{7}$ Centre on Behavioural Health, Hong Kong University, Hong Kong, China
}

Received: February 12, 2019

DOI: $10.5430 /$ jnep.v9n7p67
Accepted: February 26, 2019

Online Published: March 27, 2019

\begin{abstract}
We developed an intensive five-day training program for health professionals working in cardiac rehabilitation (CR). The training covers topics related to establishing, running, maintaining and evaluating a CR program. The aim of this study was to assess the impact of the training on health professionals' self-efficacy regarding the effective delivery of CR. From 2014 to 2018 , 167 health professionals participated in one of five training programs. Participants completed a 28-item pre- and post-training self-efficacy scale. For a sub-group, self-efficacy was re-assessed 4 months later. Factor analysis was used to identify self-efficacy domains. Paired sample t-tests compared pre- and post-training self-efficacy scores; repeated measures analysis of variance investigated change over the three time points. Variations in self-efficacy across profession, role in CR, and years of CR practice were investigated. Factor analysis identified three domains: Operational aspects of CR; Medical aspects of heart disease; and Psychosocial aspects of CR. Health professionals' self-efficacy increased significantly after training participation, across the three domains and for the total score. Effects were sustained in the 4-month follow-up. Few variations in self-efficacy trajectories by participant characteristics were identified. The study demonstrates that our health professional CR training significantly improves health professionals' confidence in a range of areas related to establishing, running, maintaining and evaluating a CR program, with immediate improvements sustained four months later. The pattern of findings was largely consistent regardless of participants' role and experience in CR. Findings highlight the benefits of this relatively brief intensive program on enhancing the capacity of the CR workforce.
\end{abstract}

Key Words: Coronary heart disease, Cardiac rehabilitation, Training, Continuing professional development

\section{INTRODUCTION}

Both in Australia and internationally, cardiac rehabilitation $(\mathrm{CR})$ is recommended for all people after an acute cardiac event. $^{[1-6]}$ Attendance at CR has been shown to improve survival and quality of life and reduce hospital readmission and length of stay. ${ }^{[6-10]} \mathrm{CR}$ aims to restore individuals to

\footnotetext{
*Correspondence: Barbara M Murphy; Email: barbara.murphy@australianhearthealth.org.au; Address: Australian Centre for Heart Health, Box 2137 Post Office, Royal Melbourne Hospital, Victoria 3050, Australia.
} 
their optimal level of physical, psychological, social and vocational well-being. ${ }^{[5,6,11]}$

CR programs differ across the world. ${ }^{[6,12]}$ In Australia, CR programs are typically centre-based and comprise 6-10 sessions held once or twice per week, involving both education and moderate intensity exercise conducted in groups. ${ }^{[13]}$ Programs are designed to involve a multi-disciplinary team of professionals $^{[2,5]}$ and to include nurses, physiotherapists, occupational/physical therapists, exercise physiologists, dieticians, social workers, psychologists, pharmacists, physicians, mental health nurses, and others. ${ }^{[6]}$ Typically, the programs are facilitated by one or two coordinators supported by a range of specialist health professionals who deliver education sessions and/or facilitate the exercise component of the group program.

It has long been recognised that the delivery of CR programs, particularly for coordinators, is a specialised task that requires a breadth of knowledge and skills across a range of areas. ${ }^{[2,6,14]}$ For example, CR program coordinators require an understanding of the physiology and pathology of the heart and the causes and comorbidities of heart disease; cardiac investigations, interventions, medications and behavioural approaches to management; occupational, psychological, cognitive and lifestyle impacts of acute events and strategies for supporting recovery in these areas; as well as skills in group facilitation, adult education, program evaluation, and physical and psychosocial screening. ${ }^{6,13,15]}$ Additionally, coordinators need the organisational and managerial capacity to ensure that quality indicators related to content and timeliness of program delivery are met ${ }^{[16,17]}$ in delivering the core components of CR. In Australia, the core components include: ensuring equity and access to services; undertaking assessment and short-term monitoring; planning recovery and longer term maintenance; facilitating lifestyle/behavioural modification and medication adherence; and undertaking evaluation and quality improvement. ${ }^{[5]}$ Many of these areas are not covered in undergraduate or post-graduate training within any specific profession.

As such, training across these areas is important for health professionals working in this field. Health professional training is designed both to improve knowledge and to build confidence, or self-efficacy, in applying that knowledge in the workplace. ${ }^{[18-22]}$ Self-efficacy refers to individuals' belief in their capacity to execute behaviours that are necessary to produce specific performance outcomes. ${ }^{[23]}$ Self-efficacy has been observed as a predictor of professional practice behaviours ${ }^{[24]}$ and as an outcome of clinical training. ${ }^{[25]}$ Selfefficacy has been studied in the training of health professionals $^{[20,22,26-28]}$ and found to improve after training comple- tion. ${ }^{[20,22,26-28]}$ Training also needs to support the translation of increased self-efficacy into positive practice change, ${ }^{[24]}$ which has been found to contribute to improved patient outcomes as a result of professional training. ${ }^{[18]}$

We developed an intensive five-day centre-based training program designed to address the required knowledge and skills for health professionals working in CR programs across Australia and have been delivering the training since 1993. The training is delivered by a team of professionals who specialise in cardiology, cardiac surgery, cardiac nursing, physiotherapy, exercise physiology, occupational therapy, psychocardiology, behaviour change, and adult learning. To date, almost 1,200 health professionals have participated in 43 training programs over 26 years.

The aim of this study was to investigate changes in selfefficacy across the areas covered in the training for health professionals who have participated in the training program. Pre and post-training self-efficacy has been measured since 2014.

\section{Methods}

The present study involved a pre/post design, with assessment of health professionals' self-efficacy before and after undertaking the training. For a sub-sample of participants, a 4-month follow-up enabled a third assessment of self-efficacy and thus investigation of maintenance of post-training improvements.

\subsection{Development of the health professional training}

The 5-day health professional training was developed in 1993 by the founding Directors of the Heart Research Centre who were experts in CR in Australia. ${ }^{[2]}$ The training was delivered several times per year during the initial 12 years, and has been delivered annually since 2005 . The training covers a range of areas (as reflected in the self-efficacy items) and has evolved over the years to integrate contemporary topics, new practice guidelines and new research evidence. Early evaluations of the program sought participant feedback on training acceptability and new areas to be included. The training delivered by the $\mathrm{ACHH}$ and evaluated here is the most comprehensive program delivered to CR professionals in Australia, and the only Australian course recognised by the International Council of Cardiovascular Prevention and Rehabilitation. ${ }^{[29]}$

\subsection{Sample, recruitment and procedure for the present study}

The sample for the present study comprised health professionals who participated in the training during the five years since 2014 when assessment of self-efficacy was introduced 
into the evaluation. In 2014 and 2015 pre and post-training evaluations were undertaken using pen and paper questionnaires before the first session and after the final session of the program. Since 2016 the pre and post-training evaluations have been completed using an online questionnaire emailed to participants prior to and after completion of the training. In two years (2014 and 2015), a 4-month follow-up using an online questionnaire was undertaken to investigate longer-term self-efficacy ratings.

\subsection{Measures}

The CR Self-Efficacy Scale addresses each of the 28 topic areas covered in the training program and was designed specifically for this training. Each item is assessed on a 5point Likert scale, ranging from 1 'not at all confident' to 5 'very confident'. Domains comprising groups of items were identified using factor analysis, as described below.

Other data collected at pre-program included participants' age, sex, profession, workplace, role in CR, years working in $\mathrm{CR}$, and employment status.

\subsection{Analysis}

Continuous variables were assessed for normality and are expressed as means and standard deviations. Exploratory factor analysis was undertaken to identify the main domains of training content assessed by the CR Self-Efficacy Scale. Parallel analysis ${ }^{[30]}$ with oblimin rotation was conducted using the "psych" package in R version 3.51. ${ }^{[31]}$ Parallel analysis is considered superior to reliance solely on eigenvalue scores and can minimise over-identification of factors based on sampling error. ${ }^{[32]}$ Items were retained on the domain on which they had the highest loading, even if the cross-loading on a second domain was within 0.2. This was considered acceptable as the purpose of the factor analysis was to group topic areas rather than to develop a validated scale to be applied in other studies, when restrictions on cross-loading would apply. ${ }^{[33]}$ Domain and total pre-, postand 4-month self-efficacy scores were calculated by summing scores across each of the domains and the full item set. Domain and total scores were then standardised by dividing the mean domain/total score by the highest possible score for that domain, then dividing by 100 , giving a percentage for each domain.

Change in self-efficacy from pre- to post-training: Paired sample t-tests were used to compare health professionals' pre and post-training self-efficacy ratings across the domains and for the total score. Repeated measures analysis of variance (ANOVA) with post-hoc tukey tests were used to investigate main and interaction effects from pre-training to posttraining for three key variables defined a priori as being po-

Published by Sciedu Press tential factors that might impact on participants' self-efficacy, namely: profession (nurse, physiotherapist, exercise physiologist, other); role in CR (coordinator, team member, other); and years working in CR ( $0-2$ years, $>2$ years). Change in self-efficacy from pre-training to four months: For two of the years (2014 and 2015), repeated measures ANOVA with post-hoc tukey tests were used to investigate main and interaction effects from pre-training to post-training, and for post-training to 4-months for two binary variables: role in CR (coordinator, other); and years working in CR (0-2 years, $>2$ years). It was not possible to investigate variations regarding profession due to small sub-sample sizes within some professions and inability to combine professions to create a binary variable.

Apart from the factor analysis, all analyses were conducted using SPSS version $24 .{ }^{[34]}$ For all analyses the significance level was set at $p<.05$.

\section{RESULTS}

\subsection{Characteristics of the sample}

Over the five years since 2014,177 health professionals participated in the training and, of these, 167 (94\%) completed the pre-training questionnaire and formed the baseline sample for the evaluation. Participant characteristics are shown in Table 1.

Participating health professionals were predominantly female and, while the majority (72\%) had a nursing qualification, a range of other disciplines was represented. Just over half worked in public hospitals and over a quarter in community health, with fewer in private hospitals and other settings. Over a third were CR program coordinators, and just under half were $\mathrm{CR}$ team members, with most of the remainder planning to work in CR in the future. Participants' role in CR varied significantly in terms of their profession $\left(\chi^{2}=13.48\right.$, $p=.036)$. The majority of CR coordinators were nurses $(85 \%)$, with a small proportion of physiotherapists $(8 \%)$ and exercise physiologists $(2 \%)$ being in the coordinator role. Physiotherapists and exercise physiologists were more likely to identify as team members (63\% and $83 \%$ respectively).

The full sample of 167 participants had worked in CR from less than one up to 14 years, with a mean (SD) of 1.95 (2.57) years. Amongst those currently working as a CR coordinator or team member $(n=136)$, the mean $(S D)$ years in CR was 2.21 (2.67), again with a range of less than one to 14 years.

\subsection{Self-efficacy domains identified through factor anal-} ysis

Exploratory factor analysis revealed the presence of three factors with eigenvalues exceeding 1 , explaining $55 \%$ of the 
total variance. The three factors were - Domain 1: Operational aspects of cardiac rehabilitation (14 items); Domain 2: Medical aspects of heart disease (9 items); and Domain 3: Psychosocial aspects of cardiac rehabilitation (6 items). The factors explained $24.7 \%, 16.0 \%$ and $14.4 \%$ of the variance respectively. The Cronbach Alphas for the three domains were $0.925,0.890$ and 0.865 respectively, all indicating very good internal consistency. Item factor loadings are shown in Table 2. Notably, the item regarding 'explaining the causes of diabetes to patients' did not load on any of the three factors: for the purpose of the later analyses, it was included in Domain 2 on the basis of face validity.

Table 1. Characteristics of the health professionals who completed the pre-training questionnaire

\begin{tabular}{|c|c|c|}
\hline Characteristics & $\mathbf{n}$ & $\%$ \\
\hline \multicolumn{3}{|l|}{ Sex } \\
\hline Female & 148 & 89 \\
\hline Male & 19 & 11 \\
\hline \multicolumn{3}{|l|}{ Professional group } \\
\hline Nursing & 120 & 72 \\
\hline Physiotherapy & 24 & 14 \\
\hline Exercise Physiology & 11 & 7 \\
\hline Aboriginal health worker & 2 & 1 \\
\hline Dietetics & 2 & 1 \\
\hline Social Work & 1 & $<1$ \\
\hline Physician & 1 & $<1$ \\
\hline Psychology & 1 & $<1$ \\
\hline Practice nurse & 1 & $<1$ \\
\hline Other & 3 & 2 \\
\hline \multicolumn{3}{|l|}{ Workplace } \\
\hline Public hospital & 89 & 53 \\
\hline Community health centre & 47 & 28 \\
\hline Private hospital & 17 & 10 \\
\hline Non-government organisation & 9 & 6 \\
\hline Aboriginal health service & 1 & $<1$ \\
\hline Other & 3 & 2 \\
\hline \multicolumn{3}{|l|}{ Role in cardiac rehabilitation } \\
\hline Member of multidisciplinary team & 76 & 46 \\
\hline CR coordinator & 60 & 36 \\
\hline Planning to work in CR in future & 22 & 13 \\
\hline Other & 9 & 5 \\
\hline \multicolumn{3}{|l|}{ Employment status } \\
\hline Part time & 75 & 45 \\
\hline Full time & 68 & 41 \\
\hline $2+$ part time positions & 22 & 13 \\
\hline Casual & 1 & $<1$ \\
\hline Unemployed & 1 & $<1$ \\
\hline \multicolumn{3}{|l|}{ Year training undertaken } \\
\hline 2014 & 44 & 26 \\
\hline 2015 & 39 & 23 \\
\hline 2016 & 27 & 16 \\
\hline 2017 & 23 & 14 \\
\hline 2018 & 34 & 20 \\
\hline
\end{tabular}

\subsection{Changes in self-efficacy after participating in the training}

Of the 167 participants who completed the pre-training questionnaire, 160 (96\%) completed the post-training questionnaire. Pre- and post-training standardised mean scores on each domain and total self-efficacy scale are shown in Table 3 and Figure 1.

As shown in Table 3, participants' self-efficacy scores increased significantly after undertaking the training, across the three domains and for the total score. Figure 1 highlights the similarity in self-efficacy scores and trajectories across the three domains.

\subsection{Variations in self-efficacy improvements pre- to post- training by participant characteristics}

Profession: For the operational domain, there was a significant main effect for profession $(\mathrm{F}=6.58, \mathrm{df}=3.155, p<$ $.001)$ and a significant interaction between profession and change over time $(\mathrm{F}=2.80, \mathrm{df}=3.155, p=.042)$. Post hoc comparisons revealed that exercise physiologists scored significantly higher than both nurses and 'others' at both time points. However, while nurses had the lowest pre-training score, they made more gains over time than the other professions, nonetheless remaining lower than exercise physiologists by post-training. For the medical domain, again there was a main effect for profession $(\mathrm{F}=6.02, \mathrm{df}=3.156$, $p=.001)$, with exercise physiologists and nurses scoring significantly higher than physiotherapists and 'others'. There was no profession by time interaction effect for the medical domain, suggesting that all professions improved at the same rate. There were no significant main or interaction effects for the psychosocial domain or the total score, again suggesting that all professions improved at a similar rate in overall self-efficacy and for the psychosocial domain.

Role in CR: Regarding participants' role in CR (coordinator vs. team member vs. other), there were no significant main effects nor were there any significant time by role interaction effects on any domain or on the total score. This suggests that participants across all CR roles scored similarly at both time points and improved at the same rate in all domains of self-efficacy.

Years working in CR: For the operational domain, there was a significant interaction between years working in CR and change over time $(F=4.50, \mathrm{df}=1.157, p=.035)$. While those with more experience in $\mathrm{CR}(>2$ years) scored higher than those with less $\mathrm{CR}$ experience ( 0 -2 years) at pre-training ( $M=64.38, M=60.92$ respectively), the less experienced made greater gains over time, with no difference between the two groups by post-training $(\mathrm{M}=84.08, \mathrm{M}=83.57)$. A similar trend was evidenced for the total self-efficacy score, with the interaction effect approaching significance $(\mathrm{F}=3.50$, $\mathrm{df}=1.157, p=.063)$. There were no significant main or interaction effects for the medical or psychosocial domains, suggesting similar improvement in these areas regardless of CR experience. 
Table 2. Factors (domains) and factor loadings for each item

\begin{tabular}{|c|c|c|c|c|}
\hline & Factor/Dom & & & H. \\
\hline & Operational & Medical & Psychosocial & omqueness \\
\hline Planning exercise sessions & 0.874 & & -0.301 & 0.286 \\
\hline Developing a CR program & 0.864 & & & 0.281 \\
\hline Monitoring patients' exercise & 0.774 & & & 0.390 \\
\hline Using clinical outcome measures & 0.756 & & & 0.414 \\
\hline Evaluating a CR program & 0.720 & & & 0.409 \\
\hline Managing a CR program & 0.696 & & & 0.487 \\
\hline Using evidence-based screening & 0.674 & & & 0.424 \\
\hline Strategies to increase attendance & 0.673 & & 0.366 & 0.336 \\
\hline Assessments to identify goals & 0.626 & & & 0.454 \\
\hline Encouraging physical activity & 0.520 & & & 0.563 \\
\hline Using behaviour change strategies & 0.515 & & 0.410 & 0.449 \\
\hline Running interactive groups & 0.458 & & 0.373 & 0.514 \\
\hline Using principles of adult education & 0.400 & & 0.393 & 0.578 \\
\hline Assessing health literacy & 0.441 & & & 0.581 \\
\hline Explaining investigations & & 0.852 & & 0.282 \\
\hline Explaining interventions & & 0.843 & & 0.323 \\
\hline Explaining pathology of CHD & & 0.730 & & 0.386 \\
\hline Explaining causes of CHD & & 0.718 & & 0.364 \\
\hline Advising patients about medications & & 0.681 & & 0.521 \\
\hline Explaining rationale of CHD management & & 0.656 & & 0.367 \\
\hline Providing dietary advice & & 0.453 & & 0.691 \\
\hline Explaining evidence for CR & 0.328 & 0.369 & & 0.611 \\
\hline Identifying \& supporting depression \& anxiety & & & 0.857 & 0.241 \\
\hline Understanding \& supporting patients’ psychosocial needs & & & 0.819 & 0.268 \\
\hline Discussing patients' feelings \& concerns & & & 0.725 & 0.347 \\
\hline Providing support to patients who smoke & & & 0.557 & 0.517 \\
\hline Supporting patients to return to work & 0.366 & & 0.390 & 0.486 \\
\hline Talking to patients about resuming sex & & 0.315 & 0.347 & 0.670 \\
\hline Explaining causes of diabetes to patients & & & & 0.792 \\
\hline
\end{tabular}

Table 3. Domain and total self-efficacy scores before and after the training

\begin{tabular}{|c|c|c|c|c|c|c|c|}
\hline \multirow{2}{*}{ Domain } & \multicolumn{2}{|c|}{ Pre-training } & \multicolumn{2}{|c|}{ Post-training } & \multirow{2}{*}{$t$} & \multirow{2}{*}{ df } & \multirow{2}{*}{$p$} \\
\hline & Mean & SD & Mean & SD & & & \\
\hline Operational domain & 60.7 & 12.46 & 82.7 & 9.45 & 21.60 & 159 & $<.001$ \\
\hline Medical domain & 61.7 & 12.76 & 83.7 & 9.18 & 22.39 & 159 & $<.001$ \\
\hline Psychosocial domain & 59.4 & 13.09 & 80.7 & 9.87 & 20.36 & 159 & $<.001$ \\
\hline Total score & 60.8 & 10.59 & 82.7 & 8.11 & 24.48 & 159 & $<.001$ \\
\hline
\end{tabular}

Note. $\mathrm{N}=160$. Statistics = paired sample $t$-tests. Each item rated on 5-point Likert scale from 1 = not at all confident to $5=$ very confident. Possible score range $=20-100$ for domains $/$ total.

\subsection{Maintenance of self-efficacy improvements four months after the training}

For the subsample of participants who attended the 2014 and 2015 training programs $(n=83), 54$ participants completed the four month follow-up questionnaire, representing a $65 \%$ Published by Sciedu Press response rate. For this sub-group, mean scores for total selfefficacy and each of its three domains increased significantly from pre- to post-training, then remained stable from postto 4 months, as shown in Table 4 and Figure 2. 


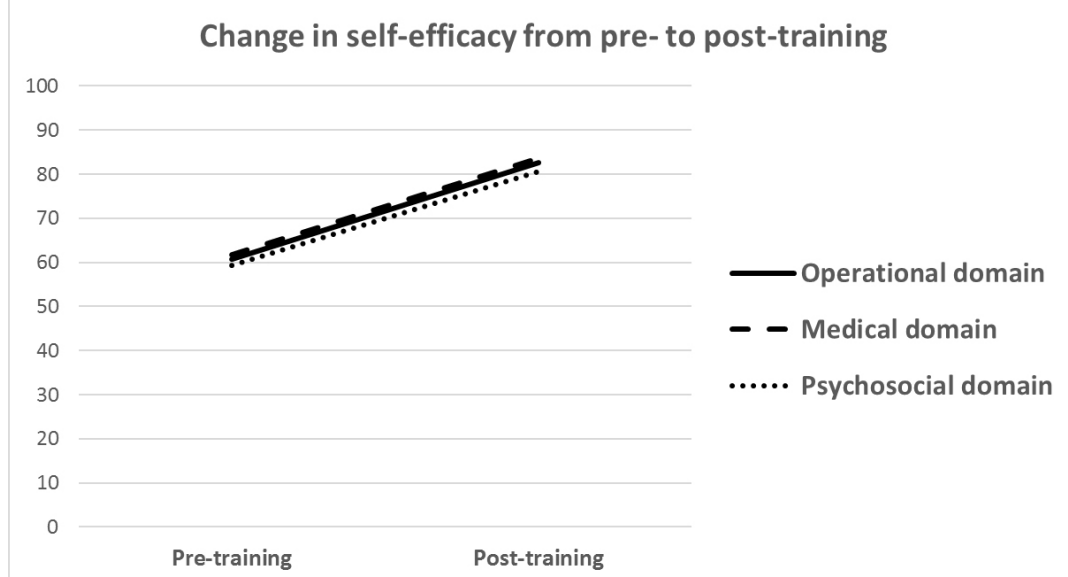

$N=159$. Possible score range $=20-100$ for each domain. Change from pre- to post-training significant for all domains.

Figure 1. Pre-training and post-training standardised mean scores for each domain

Table 4. Domain and total self-efficacy scores before and after the training

\begin{tabular}{|c|c|c|c|c|c|c|c|c|c|c|}
\hline \multirow{2}{*}{ Domain } & \multicolumn{2}{|c|}{ Pre-training } & \multicolumn{2}{|c|}{ Post-training } & \multicolumn{2}{|c|}{ Four months } & \multirow{2}{*}{ Comparison } & \multirow{2}{*}{$t$} & \multirow{2}{*}{ df } & \multirow{2}{*}{$p$} \\
\hline & Mean & SD & Mean & SD & Mean & SD & & & & \\
\hline \multirow{2}{*}{ Operational } & \multirow{2}{*}{60.9} & \multirow{2}{*}{11.03} & \multirow{2}{*}{83.8} & \multirow{2}{*}{8.33} & \multirow{2}{*}{82.5} & \multirow{2}{*}{9.14} & Pre-Post & 6.87 & 53 & $<.001$ \\
\hline & & & & & & & Post-4mth & 0.30 & 52 & .995 \\
\hline \multirow{2}{*}{ Medical } & \multirow{2}{*}{63.2} & \multirow{2}{*}{13.18} & \multirow{2}{*}{84.7} & \multirow{2}{*}{9.79} & \multirow{2}{*}{82.6} & \multirow{2}{*}{10.08} & Pre-Post & 5.20 & 53 & $<.001$ \\
\hline & & & & & & & Post-4mth & 0.33 & 52 & .942 \\
\hline \multirow{2}{*}{ Psychosocial } & \multirow{2}{*}{60.2} & \multirow{2}{*}{12.25} & \multirow{2}{*}{81.0} & \multirow{2}{*}{9.32} & \multirow{2}{*}{78.6} & \multirow{2}{*}{9.50} & Pre-Post & 5.36 & 53 & $<.001$ \\
\hline & & & & & & & Post-4mth & 0.14 & 52 & .990 \\
\hline \multirow{2}{*}{ Total } & \multirow{2}{*}{61.5} & \multirow{2}{*}{10.64} & \multirow{2}{*}{83.8} & \multirow{2}{*}{8.05} & \multirow{2}{*}{81.7} & \multirow{2}{*}{8.39} & Pre-Post & 14.29 & 53 & $<.001$ \\
\hline & & & & & & & Post-4mth & 1.32 & 52 & .388 \\
\hline
\end{tabular}

Note. $\mathrm{N}=54$. Statistics = paired sample $t$-tests. Each item rated on 5-point Likert scale from 1 = not at all confident to 5 = very confident. Possible score range $=20-100$ for domains/total.

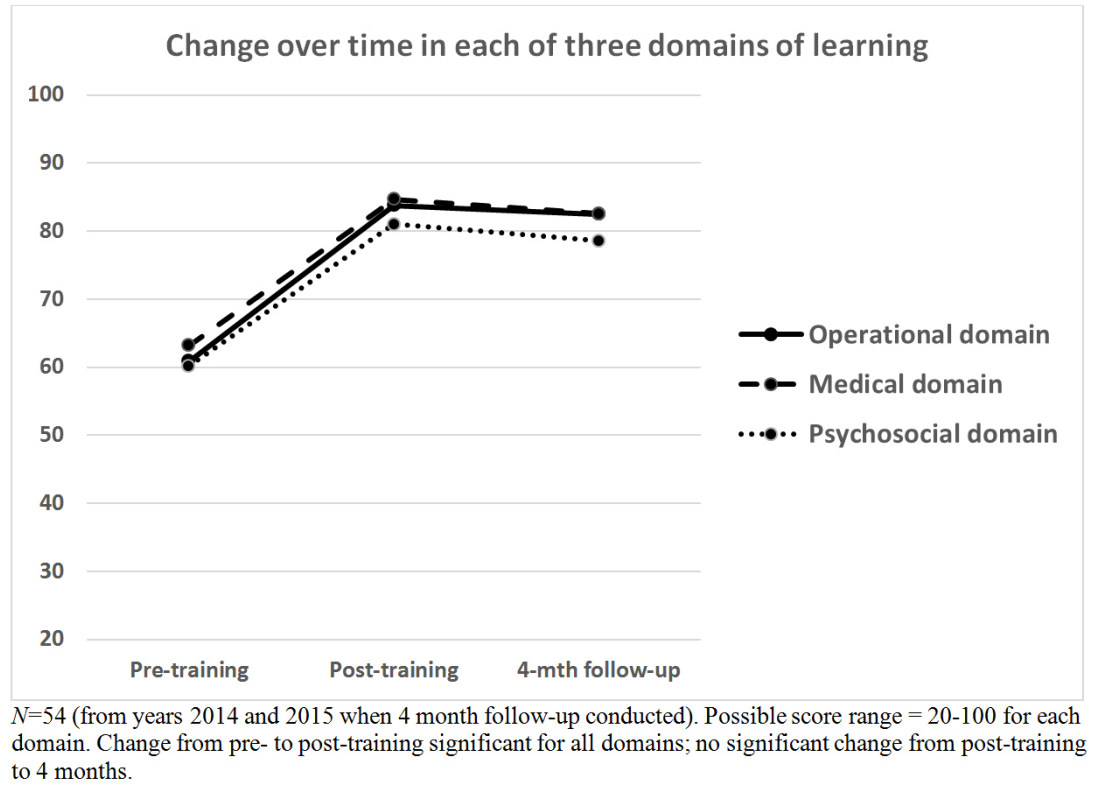

Figure 2. Pre-training, post-training and 4 month follow-up standardised mean scores for each domain 


\subsection{Variations in 4-month self-efficacy trajectories by} participant characteristics

Role in CR: Regarding participants' role in CR (coordinator vs. other), there was no main effect for either the operational domain $(\mathrm{F}=0.259 \mathrm{df}=1.48, p=.613)$, the medical domain $(\mathrm{F}=0.15, \mathrm{df}=31.48, p=.700)$ or the psychosocial domain $(\mathrm{F}=0.01, \mathrm{df}=1.48, p=.991)$, nor were there were any significant time by role interactions.

Years working in CR: Regarding years working in CR (0-2 years vs. $>2$ years), there was a main effect for the operational domain $(\mathrm{F}=4.64, \mathrm{df}=1.51, p=.036)$, with those with more $\mathrm{CR}$ experience scoring higher than those with less experience. The difference for the medical domain approached significance $(\mathrm{F}=3.28, \mathrm{df}=1.51, p=.076)$, while there was no main effect for the psychosocial domain $(\mathrm{F}=1.10$, $\mathrm{df}=$ $1.51, p=.300)$. There was no significant time by years in $\mathrm{CR}$ interactions.

\section{DisCuSSION AND CONCLUSION}

The present findings demonstrate that health professionals achieved significant improvements in self-efficacy after undertaking an intensive CR training program. These improvements were evident for each of the three domains, relating specifically to the operational aspects of establishing, running and maintaining a $\mathrm{CR}$ program, the medical aspects of heart disease, and the psychosocial aspects of CR. These findings are testament to the benefits of the training in terms of increased confidence in a range of areas required for the successful delivery of effective CR. ${ }^{[5,13,15-17]}$ Importantly, the training addresses the key areas of establishing, delivering, maintaining and evaluating a CR program, while attending to issues such as patient health literacy, effective adult education approaches, and effective group interaction.

The improvements in self-efficacy evidenced immediately post-training were also maintained four months later. This is particularly encouraging, as immediate gains in confidence can be challenged once training participants return to the workplace and encounter barriers to implementing the knowledge and skills they have gained. ${ }^{[21]}$ These challenges can include both personal and workplace-related barriers to practice change. ${ }^{[21]}$ Whilst only a small sub-sample, participants in the present study maintained their gains in self-efficacy across all three domains. Future studies could investigate actual practice changes implemented in the months after the training, and explore the facilitators of and barriers to practice change.

Importantly, improvements in self efficacy were evidenced largely across the entire participant group, with few differences based on participant characteristics. Indeed, for the

Published by Sciedu Press total self-efficacy score, there were no significant differences in improvements over time in terms of profession, role in CR, or years of CR experience. This pattern of universal benefit was seen also for the psychosocial domain. These findings highlight the benefits of the training for health professionals across a range of disciplines, years of CR experience and roles within the CR team.

There were some exceptions to the pattern of universal benefit, particularly in relation to the operational domain. In this area, exercise physiologists came into the training with greater confidence than other professions, and maintained this higher self-efficacy over time. Notably, the operational domain includes items related specifically to planning exercise sessions, monitoring patients' exercise and using clinical outcome measures, which could be considered the speciality of exercise physiologists. However, even when items related to exercise physiology specialist areas were removed from the operational domain, exercise physiologists still demonstrated higher self-efficacy than other professions (data not shown). It is possible that the topics covered in the training program evaluated here are most closely aligned to the undergraduate and postgraduate training in exercise physiology than in other disciplines such as nursing and physiotherapy.

Interestingly, those with fewer years of experience made greater gains in the operational domain than their more experienced counterparts immediately after the training, despite coming into the program with less confidence in establishing, running and maintaining a CR program. These findings suggests that health professionals with less prior experience are able to benefit equally if not more so than those with more direct CR experience and contact. Importantly though, this pattern was not evidenced in the sub-group analysis.

The role of CR coordinators and team members is a specialised one that requires a breadth of knowledge and skills across a range of diverse areas. ${ }^{[14]}$ That this breadth of training is not covered in undergraduate or post-graduate training within any specific profession in Australia underscores the importance of the ACHH training. In this intensive format, it is possible to offer the range of content covered in longer post-graduate programs such as the MSc in Preventive Cardiology at Imperial College London, ${ }^{[35]}$ although not in the same depth.

Some limitations of the study should be noted. First, the study is based on self-report which can be unreliable and prone to response bias. Second, and related to this, we did not assess actual practice changes, which could be the focus of a future more intensive evaluation. Importantly though there is evidence that self-efficacy is a good indicator of work practice. ${ }^{[24]}$ Third, our 4-month follow-up, while pro- 
ducing encouraging results, achieved only a $65 \%$ response rate. While typical in follow-ups of this kind, the response rate cautions that findings cannot be considered representative of the entire group. Moreover, the study would be strengthened by the inclusion of a longer follow-up assessment, ideally at one-year post-training, to assess maintenance of gains achieved. Others have demonstrated sustained selfefficacy improvements 18 months after health professional training. ${ }^{[22]}$ Despite these limitations, our findings provide sound evidence of the benefits of the training in terms of improved self-reported confidence regarding the effective delivery of CR.

\section{CONFlicts OF InTEREST Disclosure}

The authors declare that there is no conflict of interest statement.

\section{REFERENCES}

[1] World Health Organisation: Rehabilitation after cardiovascular disease with special emphasis on developing countries. Gevena: WHO; 1993.

[2] Goble AJ, Worcester MUC: Best Practice Guidelines for Cardiac Rehabilitation and Secondary Prevention. Melbourne: Heart Research Centre on behalf of the Victorian Department of Human Services; 1999.

[3] National Heart Foundation of Australia: Recommended framework for cardiac rehabilitation. Canberra: NHF; 2004.

[4] National Heart Foundation of Australia and Cardiac Society of Australia and New Zealand: Guidelines for Reducing Risk in Heart Disease: an expert guide to clinical practice for secondary prevention of coronary heart disease. Canberra: NHF; 2012.

[5] Woodruffe S, Neubeck L, Clark RA, et al. Australian Cardiovascular Health and Rehabilitation Association (ACRA) core components of cardiovascular disease secondary prevention and cardiac rehabilitation. Heart, Lung \& Circulation. 2015; 24: 430-441. PMid:25637253 https://doi.org/10.1016/j.hlc.2014.12.008

[6] Dalal HM, Doherty P, Taylor RS. Cardiac rehabilitation. BMJ: British Medical Journal. 2015.

[7] Beauchamp A, Worcester M, Murphy B, et al. Attendance at cardiac rehabilitation is associated with lower all-cause mortality after 14 years of follow-up. Heart. 2013; 99: 620-625. PMid:23213175 https://doi.org/10.1136/heartjnl-2012-303022

[8] Rauch B, Davos CH, Doherty P, et al. The prognostic effect of cardiac rehabilitation in the era of acute revascularisation and statin therapy: A systematic review and meta-analysis of randomized and nonrandomizedc studies - The Cardiac Rehabilitation Outcome Study (CROS). European Journal of Preventive Cardiology. 2016; 23: 1914 1939. PMid:27777324 https ://doi .org/10.1177/2047487316 671181

[9] Buckley J, Contractor A, Yeung C, et al. Cardiac rehabilitation effectiveness? A commentary from the International Council of Cardiovascular Prevention and Rehabilitation. BMJ Open. 2018; 8: e019656.

[10] Thomas E, Lotfaliany M, Grace SL, et al. Effect of cardiac rehabilitation on 24-month all-cause hospital readmissions: A prospective cohort study. European Journal of Cardiovascular Nursing. 2018.

[11] Taylor RS, Brown A, Ebrahim S. Exercise-based rehabilation for patients with coronary heart disease: systematic review and metaanalysis of randomized controlled trials. Am J Med. 2004; 116: 682 692. PMid:15121495 https://doi.org/10.1016/j.amjmed. 2 004.01 .009

[12] Lima de Melo Ghisi G, Pesah E, Karam Turk-Adawi K, et al. Cardiac Rehabilitation Models around the Globe. J Clin Med. 2018.

[13] Jackson AC, Higgins RO, Murphy BM, et al. Cardiac rehabilitation in Australia: A brief survey of program characteristics. Heart
Lung \& Circulation. 2018; 27: 1415-1420. PMid:29100840 https : //doi.org/10.1016/j.hlc.2017.08.024

[14] Fridlund B. The role of the nurse in cardiac rehabilitation programmes. European Journal of Cardiovascular Nursing. 2001; 1: 15-18. https://doi .org/10.1016/S1474-5151(01)00017-2

[15] Jackson AC, Le Grande MR, Higgins RO, et al. Psychosocial screening and assessment practice within cardiac rehabilitation: A survey of cardiac rehabilitation coordinators in Australia. Heart Lung \& Circulation. 2017; 26: 64-72. PMid:27283446 https ://doi.org/ $10.1016 / \mathrm{j} . \mathrm{hlc} .2016 .04 .018$

[16] Zeechin R, Candelaria D, Ferry C, et al. Development of Quality Indicators for Cardiac Rehabilitation in Australia: A Modified Delphi Method and Pilot Test. Heart, Lung \& Circulation. 2018.

[17] Thomas RJ, Balady G, Banka G, et al. ACC/AHA clinical performance and quality measures for cardiac rehabilitation: a report of the American College of Cardiology/American Heart Association Task Force on Performance Measures. J Am Coll Cardiol. 2018; 71: 1814-1837.

[18] Lorenz R, Gregory RP, Davis DL. Utility of a brief self-efficacy scale in clinical training program evaluation. Evaluation and the Health Professions. 2000; 23: 182-193. PMid:10947524 https : //doi .org/10.1177/016327870002300204

[19] Manojlovich M. Promoting nurses' self-efficacy: a leadership strategy to improve practice. Journal of Nursing Administration. 2005; 35: 271-278. PMid:15891491

[20] Murphy BM, Higgins RO, Shand L, et al. Improving health professionals' self-efficacy to support patients' emotional recovery after heart attack and heart surgery: The 'cardiac blues project'. European Journal of Cardiovascular Nursing. 2016; 16: 143-149. PMid:27071738 https://doi.org/10.1177/14745151166438 69

[21] Higgins R, Navaratnam H, Murphy BM, et al. Outcomes of a chronic heart failure training program for health professionals. Journal of Nursing Education and Practice. 2013; 3(7): 68-74. https : //doi.org/10.5430/jnep.v3n7p68

[22] Nørgaard B, Ammentorp JJ, Kofoed PE. Long term follow-up on health care professionals' self-efficacy after communication skills training. Journal of Nursing Education and Practice. 2013; 3(10): 91-98. https://doi.org/10.5430/jnep.v3n10p91

[23] Bandura A. The explanatory and predictive scope of self-efficacy theory. Journal of Clinical and Social Psychology. 1986; 4: 359-373. https://doi.org/10.1521/jscp.1986.4.3.359

[24] Schaufeli WB, Di Tecco C, Borgogni L, et al. What makes employees engaged with their work? The role of self-efficacy and employee's perceptions of social context over time. Career Development International. 2016; 21: 125-143. https ://doi .org/10.1108/CDI-0 3-2015-0045 
[25] Bandura A. Self-efficacy: toward a unifying theory of behavioral change. Psychological Review. 1977; 84: 191-215. https://doi. org/10.1037/0033-295X.84.2.191

[26] Farrell B, Richardson L, Raman-Wilms L, et al. Self-efficacy for deprescribing: A survey for health care professionals using evidencebased deprescribing guidelines. Research in Social and Administrative Pharmacy. 2018; 14: 18-25. PMid:28214150 https ://doi .or $\mathrm{g} / 10.1016 / \mathrm{j}$.sapharm.2017.01.003

[27] Norgaard B, Ammentorp J, Ohm Kyvik K, et al. Communication skills training increases self-efficacy of health care professionals. Journal of Continuing Education in the Health Professions. 2012; 32: 90-97. PMid:22733636 https ://doi.org/10.1002/chp. 21131

[28] Wilkinson SA, Hills AP, Street SJ, et al. Reassessment of Allied Health Professionals' Level of Self-Efficacy in, Outcome Expectancy in, and Use of Evidence-Based Practice. Journal of Allied Health. 2016; 45: 87-94.

[29] Available from: http://globalcardiacrehab.com/trainin g-opportunities/training/
[30] Horn JL. A rationale and test for the number of factors in factor analysis. Psychometrika. 1965; 30: 179-185. PMid:14306381 https://doi.org/10.1007/BF02289447

[31] R Version 3.51. The R Foundation for Statistical Computing.

[32] Wood ND, Akloubou Gnonhosou DC, Bowling J. Combining Parallel and Exploratory Factor Analysis in Identifying Relationship Scales in Secondary Data. Marriage \& Family Review. 2015; 51: 385395. PMid:26494935 https://doi.org/10.1080/01494929.2 015.1059785

[33] Tabachnick BG, Fidell LS. Using Multivariate Statistics, 7th ed. Boston: Pearson; 2019.

[34] IBM Corp: IBM SPSS Statistics for Windows Version 24.0. IBM Corp. Armonk NY; 2016.

[35] Jones J, Barr S, Jennings C, et al. Training opportunities in preventive cardiology: MSc, Diploma and Certificate in Preventive Cardiology. British Journal of Cardiology. 2013; 20(suppl 3): S1-S19. 